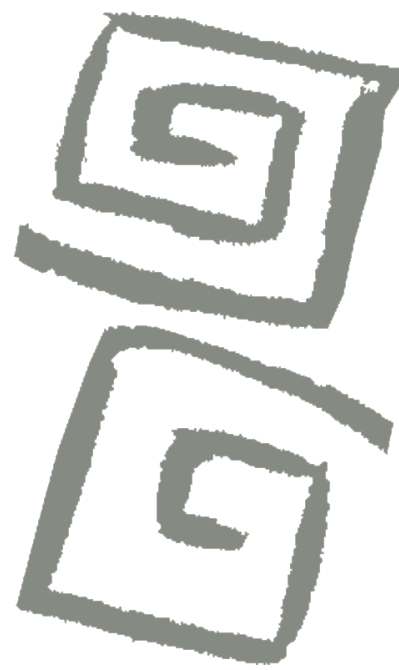

\title{
Subvertir la vulneración médica: itinerarios corporales disidentes de la discapacidad en Chile
}

\author{
Subverting medical vulneration: Dissident bodily \\ itineraries of disability in Chile
}

Juan Andrés Pino-Morán', Pía Rodríguez-Garrido², Inmaculada Zango-Martín³, Enrico Mora-Malo ${ }^{4}$

'Doctor en Sociología. Miembro del grupo de Estudios Críticos en Discapacidad (CLACSO). Jefe de carrera Terapia Ocupacional, Escuela de Salud, Universidad de O'Higgins, Rancagua, Chile. $\triangle$ (iD)

${ }^{2}$ Magíster en Atención Sanitaria y Práctica Colaborativa. Investigadora, Programa de Doctorado de Enfermería y Salud y en ADHUC-Centro de Investigación Teoría, Género y Sexualidad, Universidad de Barcelona; Barcelona, España. $\bowtie$ (iD)

${ }^{3}$ Autora de correspondencia. Doctora en Investigación Sociosanitaria. Investigadora, Grupo de investigación de la EUIT. Docente, Departamento de Terapia Ocupacional, Escola Universitària d'Infermeria i Teràpia Ocupacional de Terrassa, Barcelona, España. $\triangle$ (iD)

${ }^{4}$ Doctor en Sociología. Coordinador, Lis - Estudios sociales y de género sobre la corporalidad, la subjetividad y el sufrimiento evitable. Docente, Departamento de Sociología, Universidad Autónoma de Barcelona, Barcelona, España. $\square$ iD
RESUMEN EI reconocimiento de los cuerpos disidentes de la discapacidad ofrece una situación de continua resistencia, por lo que nuestro objetivo fue analizar la vulnerabilidad y vulneración corporal de las personas activistas de la discapacidad en Chile. Para eso, entre septiembre de 2017 y febrero de 2018, se realizaron once entrevistas en profundidad utilizando la técnica de los itinerarios corporales y seis conversatorios. A través del análisis temático cualitativo, surgió la categoría central "el cambio o diferencia corporal: experiencias de fragilidad medicalizada", y tres subcategorías: "diagnóstico corporal: la gestión institucional de las diferencias"; "tratamiento médico: corregir la anormalidad corporal y social"; y "rehabilitación: volver a funcionar como un cuerpo normativo". Los itinerarios de las personas activistas develan la coaptación y vulneración corporal a la que son sometidas al ingresar a los dispositivos biomédicos que niegan sistemáticamente sus derechos humanos. Sin embargo, a pesar de intentar disciplinar y controlar sus cuerpos, crean estrategias para subvertir y validar sus subjetividades.

PALABRAS ClAVES Activismo Político; Cuerpo Humano; Personas con Discapacidad; Vulnerabilidad Social; Chile.

ABSTRACT Acknowledging dissident bodies of persons with disabilities is an act of continuous resistance, and as such our objective in this article is to analyze the vulnerability and bodily violation of disability activists in Chile. In order to do so, between September 2018 and February 2019 we conducted 11 in-depth interviews using the technique of bodily itineraries, as well as 6 discussion groups. Through qualitative thematic analysis, several categories emerged: the central category of "Bodily change or difference: experiences of medicalized fragility;" and three subcategories, "Bodily diagnosis: the institutional management of differences;" "Medical treatment: correcting bodily and social abnormality;" and "Rehabilitation: to function once again as a normative body." Activists' itineraries reveal the coaptation and bodily violation that they are subjected to by the biomedical apparatus, where they are systematically denied their human rights; however, despite attempts to discipline and control them, they create subversive strategies to validate their corporealities.

KEY WORDS Political Activism; Human Body; Disabled Persons; Social Vulnerability; Chile. 


\section{INTRODUCCIÓN}

El presente estudio responde a los resultados encontrados con relación al primer objetivo de investigación, enmarcado en el proyecto "Cuerpo(s) en luchas: itinerarios disidentes de la discapacidad en Chile". En los últimos años, el cuerpo ha sido objeto de innumerables tensiones e intervenciones producidas bajo el mandato de la globalización neoliberal contemporánea $^{(1)}$. Hoy, cualquier sujeto que escape al ordenamiento estético, funcional, racional o económico, está seriamente amenazado de ingresar a la gran masa de personas prescindibles, desechables o deslegitimadas; por lo tanto, cada vez es mas común reconocer una situación de discapacidad como un hecho de nuestra vida cotidiana. En ese sentido, la institucionalidad y, particularmente la Convención Internacional de las Personas en Situación de Discapacidad, la entiende como

...un concepto que evoluciona y que resulta de la interacción entre las personas con deficiencias y las barreras debidas a la actitud y al entorno que evitan su participación plena y efectiva en la sociedad en igualdad de condiciones con las demás. ${ }^{(2)}$

Desde esta perspectiva, las luchas sociales del activismo y asociacionismo ${ }^{(3)}$ de las personas con discapacidad se vuelven relevantes, ya que ponen el énfasis en las determinantes sociales de su discapacitación ${ }^{(4)}$, incluyendo el impacto sistemático de las instituciones médicas en sus trayectorias. No obstante, este análisis no contemplaba la corporeidad ${ }^{(5)}$ como depositario material del malestar subjetivo ${ }^{(6)}$. A pesar de ello, en los últimos años, la sociología del cuerpo $^{(7)}$ y el feminismo de la discapacidad ${ }^{(8)}$ han puesto en escena el reconocimiento de las vulnerabilidades corporales, superando la comprensión reduccionista y esencialista del cuerpo que el propio activismo de la discapacidad ha intentado subvertir en las últimas décadas, representado por colectivos como el Movimiento de Vida Independiente latinoamericano ${ }^{(9)}$, los movimientos anticuerdistas latinoamerica$\operatorname{nos}^{(10)} y$, más recientemente, los movimientos del feminismo loco en Chile(11). Pero, sin embargo, persiste como problema epistemológico entre los estudios del cuerpo y de la discapacidad.

Producto de ello, esta investigación quiso explorar esa relación inconclusa siguiendo los itinerarios corporales ${ }^{(12)}$ de las personas con diversidades por fuera de las clasificaciones clínicas-diagnósticas propuestas por el modelo médico hegemónico y/o por su actualización mas reciente en la Clasificación Internacional de Funcionamiento, de la Discapacidad y de la Salud $(\mathrm{CIF})^{(13)}$, y analizar cómo transitan por diferentes posiciones sociales desde su primer diagnóstico-enfermedad hasta constituirse en personas con discapacidad con toda una serie de hitos, prejuicios y etiquetajes que van configurando sus identidades en ese devenir médico social.

De este modo, revisaremos cómo el ingreso al dispositivo médico ${ }^{(14)}$ implica una sujeción por años o, en algunos casos, de por vida, a una forma particular de vulnerabilidad corporal que da sentido a su conformación como activistas ${ }^{(15)}$.

La vulnerabilidad precede a las personas; sin embargo, esta premisa es comprendida históricamente en cuerpos determinados. Por este motivo, las representaciones dominantes sobre las personas en situación de discapacidad están vinculadas con la vulnerabilidad corporal, situación que paralelamente implica un tutelaje con políticas asistenciales y paternalistas que niega sistemáticamente sus derechos humanos. No obstante, lejos de negar la vulnerabilidad del colectivo, entendemos el cuerpo vulnerable no como una sustancialidad particular de un grupo o un cuerpo específico -como plantea el binarismo cisheteropatriarcal capacitista- sino más bien como una cuestión relacional, afectiva, corporal, que nos pertenece a todas y a todos. Como sostiene Butler ${ }^{(15)}$, la vulnerabilidad es considerada como resistencia, principio de igualdad, justicia, libertad e interdependencia, señalándola como la disposición de (ex)ponerse hacia el otro u otra. 


\section{El cuerpo vulnerable: agente de la disidencia de la discapacidad}

Dentro de los estudios de la discapaci$\operatorname{dad}^{(16,17,18,19,20,21)}$, se reconoce ampliamente la exclusión social que han enfrentado las personas con discapacidad en la estructura social. Sin embargo, hemos preferido resaltar la idea que han sido vulnerados y vulneradas, y no únicamente que son vulnerables. En ese sentido, creemos limitado el análisis binario centrado, principalmente, en la idea de inclusión/exclusión para comprender la situacionalidad actual que presentan estos cuerpos. Por ello, visualizamos la vulnerabilidad como un lugar común desde donde pensar de forma conjunta sus itinerarios y luchas políticas.

A partir de ahí, comprendemos los cuerpos vulnerables desde una epistemología feminista Butleriana ${ }^{(15)}$, la cual refiere la vulnerabilidad en diálogo con agencias encarnadas por fuera de la mirada victimaria tradicional de la discapacidad. Por el contrario, los itinerarios de los y las activistas están en un juego constante con agencias de resistencia por una vida posible y deseable, en la que sus cuerpos tengan espacios para materializar justicia y reconocimientos. Esta propuesta es interesante, ya que articula una relación política imprescindible entre vulnerabilidad, agencias y discursos, tejiendo un diálogo corporal de exposición, performatividad y lenguaje $\mathrm{e}^{(22)}$, en el que se inscriben los proyectos para una vida digna. Desde esta perspectiva, existe una dimensión ética y política para el trabajo de acción colectiva que realizan los y las activistas disidentes de la discapacidad que se mueven en un doble sentido de la palabra "como movimiento del cuerpo y como movimiento político" (15).

\section{El cuerpo vulnerado por el modelo biomédico hegemónico}

Los cuerpos vulnerados se dan en una estrecha relación entre una condición precaria de la vida, el sufrimiento y la vulnerabilidad del cuerpo. Esto ofrece un desafío a pensar más allá de la autonomía del sujeto liberal patriarcal, es decir, como una relación de continuidad y cuidados entre cuerpos con y sin discapacidad ${ }^{(23)}$. No obstante, esta situación enfrenta tensiones en su andamiaje en tanto existen concepciones que posicionan a las personas disidentes como cuerpos exclusivamente enfermos y pasivos ${ }^{(14)}$.

De esta manera, el modelo biomédico hegemónico predispone a los cuerpos disidentes como inhabilitados, como sujetos ignorantes de su condición y, además, como responsables unidimensionalmente de su situación. De acuerdo a Menéndez ${ }^{(24,25)}$, el adoctrinamiento biomédico hacia los sujetos fue problematizado principalmente en la década de 1970 a raíz de un grupo de actores, actrices y sectores sociales, los cuales cuestionaban las características clínicas que la medicina alopática estaba desarrollando sobre los individuos. Esto se vio reflejado, especialmente, en la constitución de las personas atendidas como objetos de enfermedad, desposeídos de autonomía mediante la medicalización de sus vidas. Así, su principal efecto fue la precarización de las condiciones subjetivas de existencia a través de la tutela obligatoria, invisibilizando sus saberes y prácticas de vida generando una normativización y control por las fuerzas sociales dominantes del capital.

De este modo, podemos hablar de la existencia de una cultura institucional biomédica que se sustenta en la construcción del conocimiento autorizado desde lógicas jerárquicas de poder reflejadas en el conocimiento válido del cuerpo biomédico ${ }^{(26)}$. Este corpus, además, implica una fragmentación entre el cuerpo y la mente, considerando al cuerpo como una máquina que se puede transformar, extraer y colocar aparatos externos sin perjuicio de la subjetividad del individuo ${ }^{(27)}$.

El trato y el tratamiento médico son formas sistemáticas de cómo se conduce la racionalidad del dispositivo biomédico para cualquier cuerpo anormal ${ }^{(28)}$. La articulación en red es su principio fundante $y$, por ello, si existe un diagnóstico, al unísono se plantea un tipo particular de tratamiento o terapia en un sentido causa-efecto. En concordancia 
con esta explicación, se desarrolla toda una serie de argumentaciones de causalidad médica que permiten justificar los diagnósticos y tratar los cuerpos disidentes.

Por lo expuesto y con la finalidad de visibilizar esta situación, el objetivo de este estudio fue analizar la situación de vulnerabilidad y vulneración corporal de los y las activistas disidentes de la discapacidad que viven en Chile.

\section{METODOLOGÍA}

\section{Diseño del estudio}

El diseño metodológico que orientó esta investigación fue cualitativo, dado que implica "una actividad situada que ubica al observador en el mundo de la vida. Consiste en una serie de prácticas materiales interpretativas que hacen visible el mundo y lo transforman" ${ }^{\prime \prime 29)}$.

Este encuadre nos permitió utilizar como técnica de investigación los itinerarios corporales propuestos por la antropóloga feminista Mari Luz Esteban, ya que "sirven sobre todo para mostrar las vidas, los cuerpos en movimiento como procesos dinámicos, abiertos y en continua transformación $y$, por tanto, singulares, contradictorios, inacabados"(12). Desde esta perspectiva, se planteó investigar y sistematizar las trayectorias vitales para mostrar inflexiones, posiciones, disputas y contradicciones que encarnan los y las activistas en sus cuerpos y vidas, ya que "a nadie ha enseñado la experiencia, hasta ahora, qué es lo que puede hacer el cuerpo en virtud de las solas leyes de su naturaleza"(30).

\section{Contexto del estudio}

La investigación se realizó en Chile, país ubicado en el extremo sudoeste de América del Sur, y subdividido en dieciséis regiones de norte a sur. De las y los activistas que se entrevistaron, ocho habitaban la zona central (Región Metropolitana en la ciudad de Santiago, y Región de Valparaíso en la ciudad de Valparaíso) y tres en la zona sur del país (Región del Bio-Bio en la ciudad de Concepción).

Cabe destacar que la centralización política y económica de Chile en su capital y ciudades aledañas, asociado a las dificultades geográficas y urbanísticas que presentan las regiones alejadas de la zona central, dificultan considerablemente la colectivización de personas en situación de discapacidad. Esta situación genera no solo complejidad en la organización, logística y comunicación de los colectivos sino, además, dificulta los procesos subjetivos de agenciamiento que cada persona en estas condiciones puede llegar a sostener. Por este motivo, las personas que se identifican como activistas disidentes de la discapacidad y que habitan en regiones que presentan adversidades geográficas, políticas y económicas, relevan la importancia de, a pesar de ello, lograr desarrollar una trayectoria agenciadora y colectivizarse.

\section{Selección y características de las y los activistas}

El acercamiento se realizó, en primera instancia, mediante invitaciones a participar a través de correos electrónicos y redes sociales de activistas referentes en el ámbito de la discapacidad. Luego, en segunda instancia, se utilizó el muestreo por bola de nieve para identificar a otras personas activistas que, pese a no ser tan reconocidas, realizan una extensa función de defensa de los derechos humanos por las personas en situación de discapacidad.

Se optó por incluir a activistas que aceptaron la invitación a participar del estudio. De este modo, sus características individuales implicaron tener una experiencia y/o identificación con el mundo de la discapacidad, independientemente de que esta provenga de una condición congénita o adquirida, sin hacer distinciones por diagnóstico sanitario; tener una presencia activa en los colectivos reivindicativos o críticos de la discapacidad en Chile; y residir en el país desde el año 2010 hasta el momento de la entrevista. Otra característica 
relevante, es que los y las activistas entrevistadas, independiente de su condición, permitieron recuperar su sentido histórico situado en las luchas sociales sobre la diferencia.

Así, una vez contactadas las personas se les explicó la finalidad de la investigación y se les solicitó la firma de un consentimiento informado para poder formar parte del estudio. En el consentimiento se detalló el objetivo y propósito de la investigación, como así también el carácter voluntario de la participación, la garantía de anonimato de la información y la confidencialidad de sus identidades. Cabe destacar que, debido al origen no institucional de la investigación, se procedió a formalizar la participación de las personas únicamente a través del consentimiento informado.

\section{Técnica de recogida de información}

El encuentro con los y las activistas se realizó a través de dos técnicas: en primera instancia, se efectuaron 11 entrevistas en profundidad a mujeres y hombres activistas que se identificaban con el mundo de la discapacidad y que habitaban la zona centro (Santiago y Valparaíso) y sur (Concepción) del país. Se eligió esta técnica ya que fue la mejor manera de acceder y conocer sus itinerarios corporales. De este modo, se llevaron a cabo entre dos a cuatro sesiones por participante, respetando en todo momento su situación y necesidades. Así también, todos los espacios fueron concertados por las y los propios activistas según su disponibilidad y tiempo. Para resguardar su identidad, las 11 entrevistas cuentan con nombres ficticios (Tabla 1).

En segunda instancia, participamos de seis conversatorios liderados por activistas disidentes de la discapacidad y desarrollados en las ciudades antes mencionadas. Los conversatorios abordaron temas relacionados con las luchas y resistencias de personas con discapacidad, la visibilidad de sus trabajos y las estrategias de intervenciones futuras como colectivo. Ambas instancias, tanto las entrevistas como los conversatorios, se llevaron a cabo entre septiembre de 2017 y febrero de 2018 (Tabla 2).

\section{Criterios de rigor metodológico}

Como criterios de calidad de la investigación, se utilizaron los de flexibilidad y relevancia, en tanto las comprensiones recogidas en las narrativas de los y las activistas justifican y dan respuesta al objetivo de estudio, junto

Tabla 1. Perfil de los y las activistas. Chile, septiembre 2017 y febrero 2018.

\begin{tabular}{|lccll|}
\hline Nombre ficticio & Sexo & Edad & Vínculo con el mundo de la discapacidad & Colectivo \\
\hline Julio & H & 50 & Sobreviviente de la psiquiatría & Autogestión Libre-Mente \\
\hline Guillermo & H & 33 & Baja visión & Colectivo Palos de Ciegos \\
\hline Esteban & H & 58 & Baja visión & Colectivo Palos de Ciegos \\
\hline José & H & 50 & Sobreviviente de la psiquiatría & Corporación voces \\
\hline Ricardo & H & 40 & Sobreviviente de la psiquiatría & AESAM \\
\hline Hugo & H & 45 & Sobreviviente de la talidomida & Colectivo Talidomida \\
\hline Erika & M & 40 & Ceguera/sordera (parcial) & ODISEX \\
\hline Karina & M & 55 & Sobreviviente psiquiatría & COMUNIDIS \\
\hline Elisabeth & M & 34 & Distonía generalizada & Corporación Distonía \\
\hline Beatriz & M & 55 & Amputada múltiple & Corporación Bio-Bio \\
\hline Francisca & M & 36 & Neurodiversidad & Mil Capacidades \\
\hline
\end{tabular}

Fuente: Elaboración propia. 
Tabla 2. Conversatorios de los y las activistas. Chile, septiembre 2017 y febrero 2018.

\begin{tabular}{lll} 
Nombre del conversatorio & Ciudad & Región \\
Salud mental psicosocial & Viña del Mar & Quinta \\
\hline Anti Estigma & Concepción & Octava \\
\hline Infancias diferentes y educación neoliberal & Santiago & Metropolitana \\
\hline Activismo y movimientos sociales & Santiago & Metropolitana \\
\hline Lógicas del manicomio & Santiago & Metropolitana \\
\hline Más allá del manicomio químico & Santiago & Metropolitana \\
\hline Fuente: Elaboración propia. & &
\end{tabular}

con permitir nuevos hallazgos contribuyendo a fortalecer el análisis teórico, conceptual y metodológico abordado(31).

Además, se adoptaron los criterios de accesibilidad universal y diseño para todos y todas $^{(32)}$ en tanto respondió a la versatilidad de personas que representan diversidades físicas, sensoriales y cognitivas, lo que permitió dialogar con mayor fluidez las distintas disposiciones corporales de los y las activistas al momento de las entrevistas y conversatorios.

\section{Análisis de la información}

Las entrevistas fueron transcritas de forma literal y analizadas a medida que se iban realizando, de modo que esto permitió identificar aspectos a tener en cuenta en entrevistas posteriores. Asimismo, los conversatorios fueron transcritos literalmente para su posterior análisis.

Para analizar las transcripciones de las entrevistas y de los conversatorios se utilizó el programa Atlas ti 8.2.3 versión en español. La técnica de análisis utilizada fue el análisis temático cualitativo planteado por Braun y Clarke, ya que permite "interrogar a los patrones dentro del significado personal o social en torno a un tema, identificando conductas dentro y entre los datos en relación con la experiencia vivida"(33). Además, se trabajó con una estrategia intertextual de carácter subjetiva, en tanto cada enunciado fue interpretado en función de las características del sujeto que produjo el discurso ${ }^{(34)}$.
De este modo, emergió una categoría central de análisis: "el cambio o diferencia corporal: experiencias de fragilidad medicalizada", y tres subcategorías: "diagnóstico corporal: la gestión institucional de las diferencias"; "tratamiento médico: corregir la anormalidad corporal y social"; y "rehabilitación: volver a funcionar como un cuerpo normativo".

\section{RESULTADOS Y DISCUSIÓN}

Cuando se analizan los recorridos de activistas disidentes de la discapacidad, se identifican diferentes trayectorias y sentidos que configuran el devenir de sus cuerpos y luchas. De este modo, el cuerpo vulnerable ${ }^{(15)}$ nos entrega una posicionalidad particular para interpretar sus itinerarios corporales ${ }^{(12)}$. Esta condición de base sitúa a las personas en un circuito que se inicia con un cambio o diferencia corporal.

Por cambio corporal, nos referimos cuando la corporeidad de una persona se transforma en el curso de vida o producto de alguna situación inesperada presentando un nuevo funcionamiento social. Por otro lado, la diferencia corporal, la entendemos como la condición corporal no estándar expresada desde el nacimiento y que, en ambas situaciones, pueden dar como resultado una situación de discapacidad para el pensamiento heterosexual dominante ${ }^{(35)}$. 


\section{El cambio o diferencia corporal: experiencias de fragilidad medicalizada}

En todas las trayectorias de los y las activistas disidentes de la discapacidad, la corporeidad ${ }^{(7)}$ se transforma en una experiencia encarnada de vida precaria ${ }^{(36)}$ que, a su vez, expresa una posición aumentada de vulnerabilidad. Esta situación se agudiza por las condiciones sociales que instala el neoliberalismo patriarcal en nuestro sentido común, en nuestro cuerpoterritorio $^{(23,37)}$ y en los espacios geopolíticos de alteridad latinoamericana ${ }^{(38)}$.

Una mujer activista -sobreviviente de la psiquiatría- relata cómo pasó de una situación de aparente "normalidad" cotidiana a una experiencia corporal impensada:

La verdad es que yo trabajaba estable. Sin embargo, algo estaba pasando con eso, no me di cuenta, yo trabajaba largas horas, no tenía espacio para las cosas que después vi que eran fundamentales para nuestra vida y la realidad es que se me comenzó a generar un problema nervioso y la posibilidad de tener un problema [...] de alguna forma, yo pensé que eran cosas que en realidad estaban, que no eran tan difíciles de enfrentar. Hasta que me dio la crisis de pánico. De un día para otro empiezo a tener crisis de pánico, yo llegué a la urgencia de una clínica... un día, después de que estando en mi casa a las diez de la noche tomándome un té, sentí que me estaba muriendo. Así de simple. Una cosa que no había sentido nunca y de repente tuve la sensación de que algo me estaba pasando, si me preguntan qué, no sé, pero yo sentía que me iba a morir, no podía estar tranquila, estaba en pijama, me vestí, agarré un taxi... yo me estaba muriendo. (17:7)

Esto permite identificar con claridad de qué modo las condicionantes sociales en las cuales se desenvuelve la activista impactan finalmente en un sufrimiento corporal de impensada envergadura. Asimismo, cuando se interpretan los condicionantes sociales del trabajo actual en el marco de una organización neoliberal que busca una productividad acrecentada, se demanda que las y los trabajadores tengan que permanecer largas jornadas laborales, acarreando paulatinamente un desequilibrio ocupacional| ${ }^{(39)}$. Este desequilibrio es una expresión del desajuste entre las actividades de la vida diaria, el ocio y la recreación de las personas. En ese sentido, podemos apreciar la reproducción de los mandatos hegemónicos asociados al género femenino: la producción de personas "sanas", la conformación de una familia heterosexual y el trabajo extenuante que representa el éxito neoliberal los que pasan a ser los pilares fundamentales para un régimen cisheteropatriarcal capacitista ${ }^{(40)}$.

Cuando se piensan los cuerpos vulnerables, también problematizamos la vulnerabilidad como producto o resultado de las condicionantes sociales y culturales que producen mayor accidentabilidad y crisis. Así lo refiere una mujer activista que perdió una extremidad inferior y superior en un accidente de tránsito en su infancia:

Con mis hermanas nos quedamos solas porque mi madre había ido a un centro de madres de la iglesia [...]. Entonces, me dice mi hermana, "sabes, va a llegar mi mamá y no hay pan". Y eso significa, salir del barrio, cruzar la línea [tren] y salir a comprar pan para Prat [sector]. Y la cárcel de Concepción está ubicada en Chacabuco setenta. Y mi hermana, "pucha, no quiero ir", mi hermano mayor no quería ir solo y dice, "la Toñi [nombre ficticio] va, la Toñi puede acompañarte", y yo no sé si hay un sexto sentido que te avisa cosas y dije que no, por primera vez en mi vida me opuse y dije, "sabes qué, yo no voy a ir, yo no quiero ir, yo no quiero ir", para que mi hermano mayor no fuera solo, tenía como nueve años. Entonces, me dice mi hermana, "es que tenís que ir, yo soy tu hermana mayor, yo estoy a cargo de ustedes y tienen que ir", dije, "por favor, no me obligues porque no voy a $i^{\prime \prime}$. [...] la cárcel pública, antes 
tenía unos sectores que la gente podía redondear por arriba y nosotros con los niños siempre ocupábamos esos espacios para correr, para jugar porque no había espacios donde los niños pudieran jugar... Bueno, y entre eso me encontré con unas vecinas y claro, cuando yo crucé por ahí había unas cosas que yo las pisé y una niña me dijo "quién pisó estas cuestiones", y la niña me dice "itú fuiste!", y mi hermano preocupado me dice, "arranquemos". Ya, de vuelta pa la casa y no compramos pan, ni una cuestión. Y ya pos, yo venía preocupada de dónde se había ido mi hermano porque nos separamos, incluso yo iba Ilorando de miedo porque la niña me iba a alcanzar y me iba a pegar, me acuerdo siempre, y daba vuelta miraba para atrás y no se veía nada; y había un tren, una máquina sola y que estaba parada, entonces, la gente empezó a caminar, a cruzar y delante de mí, cruzó una señora con dos niños a un lado y otros tres al otro lado, yo, detracito de ella venía. En una de esas el maquinista hace marcha atrás y yo no alcanzo a salir porque la señora tira a sus hijos hacia adelante y ahí me agarró el tren. Ahí me agarró el tren. Pero yo me acuerdo absolutamente de todo, cómo me pasó primeramente por la pierna y después por el brazo la rueda del tren, incluso había chicas que me habían visto y que se habían quedado pegadas, y yo me traté de parar, dije "por favor", me traté de parar, pensé que estaba soñando, me caía, y le dije, "oye, anda a mi casa y dile a mi hermana mayor que me venga a ver lo que me pasó". Y el tren siguió. (7:4).

Esta gráfica descripción refleja cómo las dinámicas sociales y familiares se entrecruzan con las condiciones de clase y su organización urbanística al interior de las ciudades. Explicitar las desigualdades e inequidades en las relaciones espaciales, ha sido una perspectiva ampliamente trabajada durante décadas por David Harvey ${ }^{(41)}$ cuando piensa la geografía de la diferencia, que al igual que el Movimiento de Vida Independiente ${ }^{(42)}$, luchan por una accesibilidad universal e intercultural a los diferentes territorios.

El sector urbano descrito por la activista aún es problemático en la ciudad de Concepción, en la que se siguen repitiendo problemas de tráfico vehicular y accidentes asociados a la peligrosidad de la línea del tren, hostil a un urbanismo atento a las necesidades de la diferencia y sus causas. Se trata de una zona que se encuentra lindando un barrio popular con escasa protección social, seguridad e infraestructura urbanística, lo que impide -como describe la activista y la geografía feminista ${ }^{(43)}$ - habitar un espacio saludable para el ocio y la recreación de las personas, las familias, las niñas y los niños del barrio. El traumático accidente y su consiguiente cambio corporal significó perder dos extremidades. Sin lugar a duda, este desafío implicó aprender a funcionar y moverse de una manera radicalmente diferente con su cuerpo y su ciudad.

\section{Diagnóstico corporal: la gestión institucional de las diferencias}

El cambio y la diferencia corporal tienen relación con el ingreso a una forma particular de explicar los cuerpos. Así, "el diagnóstico" pasa a ser un instrumento institucional de evaluación corporal que establece un mecanismo social para ordenar, analizar, e interpretar las trayectorias corporales de las y los activistas que se entrevistaron. Para ello, se establece una separación entre lo normal y lo patológico ${ }^{(44)}$ en una línea divisoria que permite explicar la introducción de una razón clínica disciplinante ${ }^{(26)}$ para observar, jerarquizar y tratar la diferencia corporal.

Con la introducción de una explicación clínico-científica sobre el cambio corporal aparece todo un dispositivo médico ${ }^{(45)}$ que dirige los itinerarios corporales de las personas. De acuerdo con este dispositivo médico, las personas pasarán, primero, a tener diagnósticos, tratamientos, rehabilitaciones, y luego o paralelamente, una situación de discapacidad. Esta serie de mecanismos disciplinantes 
establecen una red de relaciones entre diferentes elementos heterogéneos: disciplinas, instituciones, profesionales, saberes científicos, derivaciones, tecnologías, por los cuales transitarán las vidas e identificaciones personales y colectivas de las y los activistas.

Para diagnosticar, es necesario especificar de manera directa e independiente su causalidad. En este mecanismo operan los signos y síntomas que dan lugar a los diagnósticosenfermedades; sin embargo, esta situación se vuelve aún más compleja cuando se ejecuta esta ecuación con las Ilamadas "alteraciones de comportamiento" o en las "diferencias subjetivas" de la población ${ }^{(6)}$. Este activista explica cómo procede su historia personal al ingresar al mundo de la psiquiatría, ejemplificando sus transformaciones "diagnósticas" y las repercusiones corporales que sufrió:

Efectivamente, a los diecinueve, veinte años, empiezo a tener problemas de la adolescencia y caigo en la psiquiatría. Entonces, la psiquiatría rápidamente me diagnostica y me medica. Y ahí entro en un submundo, donde viví veinticinco años psiquiatrizado... con diagnóstico severo de asperger, no asperger, border line, y todas las depresiones, depresión endógena, profunda y todas esas cosas que hacen. Después llegué a border line, después me dieron... un trastorno neuro vegetativo, que era el único caso en Chile, uno de los mejores psiquiatras de este país, supuestamente, el doctor [XXX]. Después el diagnóstico, durante más de quince años, fue de bipolar tipo dos y el último tiempo era de bipolar con esquizofrenia... y bueno, uno siente un vacío, una pena, una pena inexplicable. A nivel corporal, fatiga física, decaimiento, exceso de pensamiento, confusión, trastorno del sueño, dificultad para enfocar la mente, deseo de llorar, deseo de hablar, esa es la angustia. (4:14)

Con esto, se evidencia cómo la racionalidad del poder psiquiátrico ${ }^{(46)}$ delimita los problemas sociales y subjetivos para transformarlos en enfermedades individuales. La entrada al submundo es una sujeción de por vida -en esta experiencia, son veinticinco años- en la que el cuerpo va incorporando y sosteniendo un régimen muy complejo por donde vislumbrar y desarrollar un proyecto de vida saludable, en todas sus dimensiones, que pasa a ser un imposible.

El deterioro emocional, cognitivo y social que exponen las corporeidades en las trayectorias psiquiátricas, hace que estas sean experiencias difíciles de sobrellevar. En esta ocasión, vemos cómo el diagnóstico nunca es "objetivo", "único" e "inmutable", sino más bien, se va transformando en una serie de nuevas categorías y etiquetas que el propio cuerpo debe incorporar y reproducir. El activista, además, relata cómo el dispositivo médico va subjetivando su comprensión de la realidad cuando va introyectando la "conciencia de enfermedad". Se trata de un recurso médico, trabajado ampliamente $y$, en especial, en los espacios sanitarios de salud mental para generar adhesión al dispositivo clínico, teniendo por efecto confirmar la hipótesis dominante de que su diagnóstico psiquiátrico es una tragedia individual de orden neurobiológico.

Este modelo explicativo ha sido ampliamente criticado por toda una corriente vinculada a la antipsiquiatría desde la década de 1960 en adelante ${ }^{(47,48,49,50,51)}$, como así también de la no psiquiatría ${ }^{(52)}$, quienes plantean la imposibilidad de una relación lineal entre las causas neurocientíficas y la conducta humana. Por lo tanto, cuestionan la supuesta cientificidad del saber psiquiátrico. Un activista reflexiona:

Yo en ese tiempo pensaba y decía "qué terrible mi enfermedad..." es una enfermedad que se va agravando y se va mutando porque claro, las manifestaciones con el tiempo iban cambiando y el diagnóstico también iba cambiando. No es que a alguien le digan, "oiga, usted tiene tal enfermedad y lleva veinte, treinta años tratándose esa enfermedad", no, mi enfermedad cambiaba en las manifestaciones, síntomas, cambiaba en los medicamentos, drogas, cambiaba 
en el diagnóstico, etiquetas, me lo iban cambiando. Entonces a mí me dejaba bastante perplejo, y yo decía: "bueno, cómo enfrento esto, si en la medida que yo voy conociendo algo, como que aparece algo nuevo". La verdad es que la siquiatría se imponía con, "no, es que lo tuyo es complejo, es difícil, cuesta diagnosticarlo". Claro y yo compraba esa cuestión, les compraba, claro, que en realidad el problema era yo. (4:15)

La perplejidad es una emoción compleja que genera una inmovilización al cuestionar los fundamentos explicativos del modelo psiquiátrico dominante generando, a su vez, desesperanza para el proyecto de vida. Este mecanismo termina responsabilizando de manera individual a la persona de todo el malestar subjetivo, generando la sensación de un manto de vidas desperdiciadas ${ }^{(1)}$. En este punto se produce una clara convergencia entre los diagnósticos psiquiátricos y el modelo de responsabilidad individualista neoliberal.

En otras situaciones, vemos cómo el proceso del diagnóstico es lapidario en cuanto a las esperanzas y posibilidades futuras y es comunicado de esa manera en los primeros estadios. Esto es una forma en la que el saberpoder-médico se posiciona en relación con la otra persona. Un ejemplo de esta situación nos la relata un activista ciego sobre su experiencia cuando le entregan la noticia de su situación y su "diagnóstico":

Entonces, yo ya tenía una fuerte miopía y, además, esto se había agravado por lesiones en torturas, entonces, entré a estudiar a esa edad, a los cincuenta años. Ya, muy miope. Y llegué a un punto, cuando estaba en segundo año de trabajo social, en que el oftalmólogo dice, "mira, aquí ya no hay nada más que hacer, no hay operación, no hay tratamiento, no hay nada" ... la cosa es que eso me significó un gran shock, me deprimí, el sueño de mi vida se enfrentaba a una barrera ahí. Me acuerdo de que una joven, yo tenía puros compañeros veinteañeros, yo era el viejo de la universidad y una chiquilla me dijo, "bueno, te encontraste con tu límite, ahí está tu límite". Y en esta situación traté de buscar algún psicólogo que me ayudara en esto, en esta situación de depresión, de angustia, de ver el futuro, literalmente, negro. (1:151)

La experiencia diagnóstica se internaliza corporalmente a través de las representaciones dominantes de lo que implica cualquier enfermedad y se acentúa cuando se trata de las facultades sensoriales primordiales para el desempeño cotidiano. El saber-poder jerarquizado en la institución médica establece el mandato de que "no hay nada más que hacer", limitando toda proyección de vida futura. Esto se traduce en una muerte prematura y en un duelo que hay que asumir con rapidez. Así, la depresión, la desmotivación y el decaimiento emocional pasan a ser una respuesta lógica. Esta situación se agudiza cuando el contexto social naturaliza las diferencias corporales de funcionamiento como deficitarias y limitantes. Una naturalización que se traduce en un asunto de responsabilidad individual, sin ningún tipo de cuestionamiento a las estructuras discapacitantes de la sociedad.

\section{Tratamiento médico: corregir la anormalidad corporal y social}

El trato y el tratamiento médico son formas sistemáticas de cómo se conduce la racionalidad del dispositivo médico. Como mencionábamos, su articulación en red es su principio fundante, ya que actúa en un sentido causaefecto. Así, se desarrolla toda una serie de argumentaciones de causalidad médica que permiten justificar los diagnósticos y tratar los cuerpos disidentes desde el paradigma de la normalidad capacitista.

De este modo, a través de la producción de dicotomías sano/enfermo, hombre/mujer, blanco/negro, capacitado/discapacitado, se van diseñando identidades en las que la segunda categoría de cada binomio queda constituida desde lo inferior, patológico y 
amenazante para el orden social y, por lo tanto, apto para ser intervenido desde un dispositivo institucional ${ }^{(53)}$.

En la mayoría de las trayectorias de las personas entrevistadas, la intervención psicofarmacológica-como tratamiento- es central para intervenir diferentes corporeidades, quedando de manifiesto las tensiones existentes entre los enfoques clínico-médicos y las intervenciones psicosociales que pasan a ser secundarias y periféricas.

En la siguiente experiencia, un activista -superviviente de la psiquiatría- comenta su interpretación con respecto al trato y tratamiento médico que recibió:

No recibí de ahí la ayuda que yo esperaba, aunque se supone que estas son las personas que me pueden decir, explicar lo que me pasa y además ayudarme en ese proceso. Recibí de vuelta lo que la mayoría de la gente recibe, un diagnóstico o varios diagnósticos, en mi caso, casi exclusivamente un tratamiento farmacológico por varios años, de varios medicamentos, en diferentes dosis. Y cuando pasó un tiempo, empecé a darme cuenta de que, a pesar de que yo había desarrollado esto que se llama "conciencia de enfermedad y adherencia al tratamiento", es decir, yo creía que era un enfermo mental, que tenía un desequilibrio químico en el cerebro y que tenía que tomar drogas psiquiátricas de por vida -eso es lo que yo hice por siete años- no estaba obteniendo los resultados que se supone que tenía que obtener, en primer lugar. $Y$, en segundo lugar, estaba teniendo problemas importantes que no me permitían tener una calidad de vida, si es que existe ese concepto también, más o menos razonable: sobrepeso, graves problemas de memoria, disfunciones sexuales, relacionales, de todo un poco, lo que le pasa a la mayoría de la gente que sigue el modelo biomédico, el modelo psiquiátrico al pie de la letra. (16:24)
En esta experiencia se destaca una paradoja de lo que significa un tratamiento médico que, supuestamente, busca el bien de la persona atendida, aunque sus efectos parecen indicar lo contrario. Así, el tratamiento principal está anclado al suministro de drogas psiquiátricas que se van manejando en dosis variables siguiendo el criterio de "conciencia de enfermedad", de este modo se ajustan según la siguiente triada: conciencia de enfermedad, tratamiento psicofarmacológico y sometimiento del cuerpo.

Por otra parte, la experiencia corporal asociada al tratamiento psicofarmacológico y sus consecuencias en el peso, la sexualidad y las relaciones sociales son efectos discapacitantes de los mal Ilamados "efectos secundarios" $^{\prime(54)}$. Estos efectos tienen poca relevancia desde la clínica, sobre todo, cuando el énfasis tiene una región especial del cuerpo: el cerebro y su funcionamiento neuroquímico. Un activista añade las consecuencias corporales que tuvo al momento de someterse a un tratamiento médico psiquiátrico:

Yo recuerdo los efectos secundarios, imagínate, yo tenía problemas de memoria, problemas de concentración, tenía un sobrepeso tremendo, tenía un temblor de manos, del cuerpo, tenía fatiga física. Y todo lo asociaba a mucha soledad, mucha discriminación. Yo pasaba acostado, lo que más recuerdo es acostado, yo no tenía ninguna incidencia en lo que había ocurrido y no tenía ninguna incidencia en la solución. Solamente me tenía que tomar la pastillita. (4:52)

Los efectos en la dimensión corporal de los eufemísticamente Ilamados "efectos secundarios" de los psicofármacos instituyen un régimen corpóreo fundado en el poder-saber psiquiátrico que establece una jerarquía entre cuerpos "capaces" y cuerpos "discapacitados". Un régimen de verdad que asigna de forma naturalizada la superioridad moral de las decisiones que toma la psiquiatría sobre la vida de las personas. Con esto, es importante resignificar estas consecuencias como primarias y no solo secundarias, como quiere 
presentarlas la medicina. Así, los temblores, la fatiga, mantener el cuerpo recostado por largos periodos, no puede sino demostrar todos los efectos discapacitantes de esta forma de reproducción corporal.

El fundamento de la superioridad moral del poder-saber psiquiátrico requiere de la instauración de la incapacidad moral para la toma de decisiones de las personas diagnosticadas. Esta situación se ve en diferentes investigaciones que manifiestan la pérdida de capacidad jurídica y de derechos que se enfrentan las personas con un diagnóstico psiquiátrico ${ }^{(55,56)}$.

Esta situación ocurre con mayor frecuencia en mujeres con diversidad psicosocial, quienes se ven enfrentadas a peores tratos y sometimientos al interior de la esfera mé$\operatorname{dica}^{(40,57)}$, esto indica el sesgo de género del poder-saber psiquiátrico ${ }^{(58)}$ expresados en los dispositivos de salud mental. Así también lo ratifica en su experiencia una activista que ingresó voluntariamente a un dispositivo sanitario:

En primer lugar, nunca se me dijo..., o sea yo fui personalmente en forma voluntaria, no era cosa que..., usted no va a encontrar en la psiquiatría en Chile que haya gente que voluntariamente vaya y se deje internar y diga, "ya, me quedo aquí". Segundo, nunca se me dijo cuál era mi diagnóstico, ni cuál era mi esperanza de vida, mis posibilidades de poder resolver mis problemas de persona, como profesional, como persona humana, después de estar con un diagnóstico; nunca se me dijo las consecuencias de qué es vivir con un diagnóstico de persona con discapacidad psicosocial: nunca. Ninguno me dijo, en los cuarenta días, cuál era mi diagnóstico, ninguno. Ninguno me explicó qué significa ser una persona con discapacidad psicosocial. Ninguno. (6:86)

Esta serie de hitos son un ejemplo de cómo se establece el trato médico sexista con las mujeres "psiquiatrizadas". Por este motivo el colectivo feminista chileno, acuña la identificación "no es lo mismo ser loco que loca" para visibilizar cómo las opresiones del género juegan un rol fundamental en la psiquiatrización de las personas ${ }^{(59)}$.

\section{Rehabilitación: volver a funcionar como un cuerpo normativo}

La rehabilitación y la habilitación son un eje central dentro del colectivo de las personas disidentes de la discapacidad y una de las últimas instancias directas que opera el dispositivo médico en el cuerpo vulnerable. Esto hace que tanto la rehabilitación como la habilitación puedan ser pensadas como una extensión particular del trato y tratamiento médico con la diferencia corporal.

En este espacio es donde se configura y explica el modelo predominante de la situacionalidad de las trayectorias de los y las activistas descrito ampliamente en la bibliografía de los estudios de la discapacidad, tal y como sostiene el modelo rehabilitador o médico ${ }^{(14,17,19)}$, si existe un problema médicocientífico no necesariamente se tiene que curar sino, más bien, es obligatorio reparar o rehabilitar. En síntesis: normalizar aplicando una ley y una norma corporal.

Sin embargo, la mayoría de las críticas al modelo rehabilitador propuestas por el activismo no tienen por interés desestimar las necesidades puntuales y transitorias de rehabilitación que puedan requerir algunas experiencias corporales, sino cuestionar la comprensión dominante de que el problema de las personas en situación de discapacidad tiene una única explicación y solución a través de la esfera médica, sanitaria y rehabilitadora, omitiendo e invisibilizando los problemas sociales, culturales, económicos y políticos que estructuran las raíces de sus conflictos y situaciones. Una activista cuenta su experiencia de cómo transitó en etapas rehabilitadoras y su tensión con la normalización:

No me imaginaba. O sea, soñaba obviamente, y cuando me decían que había prótesis, yo me las imaginaba como una pierna normal para uno. O sea, chuta, 
a mí me gustaría tener una pierna. Yo dije entre mí, "bueno tengo que seguir adelante no más", y resulta que la doctora me dice "sabes qué chiquilla, te voy a poner un pilón. Un pilón era un palo de madera con yeso. Ya pos. "Pero sabes qué, hijita, te voy a hacer un gran favor para tú columna y te vas a ir preparando para cuando tengas que ponerte la prótesis". Y en eso estuve parte de la enseñanza básica, parte de la enseñanza media, hasta primero y segundo medio. Pero tenía un problema, que se pasaba el tiempo y tanto caminar, porque yo trataba de hacer mi vida normal, se rompía rápidamente el yeso para arriba y ahí quedaba yo parada, adonde sea, quedaba. $Y$ ahí tenía que pedir ayuda, irme a la casa y al otro día ir donde la doctora. (7:11)

La experiencia de esta activista muestra el nivel de precarización de la rehabilitación que existía en Chile en las décadas de 1980 y 1990. Las esperanzas que tenía sobre su futuro y la ausencia de políticas públicas para este colectivo generaron la necesidad de demandar el derecho a la rehabilitación, la cual fue y sigue siendo uno de los tópicos de lucha por parte del activismo.

La promulgación de la Ley 20.422 en 2010, que establece "Normas sobre igualdad de oportunidades e inclusión social de personas con discapacidad"(60), destaca entre sus principios la participación y el diálogo social; sin embargo, el colectivo reconoce la ausencia de una normativa jurídica práctica que pueda materializar lo dispuesto en la ley. Esto refleja el nulo interés por parte del Estado y sus instituciones para generar un proceso democrático y dialogizante con todos sus ciudadanos.

Por su parte, la rehabilitación en Chile tiene una larga trayectoria de precariedad desde sus inicios, esto sirvió para justificar la construcción social de una cultura de beneficencia y caridad asociada a la rehabilitación por fuera de cualquier comprensión de derecho garantizado por el Estado. Así, a través de alianzas público-privadas, el colectivo ha tenido que lidiar con modelos y enfoques opuestos. Esta tensión hace difícil desmontar una de las organizaciones más reconocidas a nivel nacional sobre rehabilitación, y que surgió en el contexto de la dictadura cívicomilitar, este es el caso de "Teletón".

Esta organización trabaja principalmente con niñas, niños y adolescentes, se caracteriza por la recolección de fondos a través de una campaña televisiva muy popular, que se realiza una vez al año. Tiene un impacto mediático en la construcción cultural del cuerpo capaz muy perverso, tal como nos comenta una activista:

Yo, cuando niña [...] me acuerdo de que incluso cuando salíamos con los compañeros en la silla de ruedas: "mira ahí hay un teletón, hay un teletón". Entonces, no te identifican como persona, te identifican como teletón. $Y$ nosotros nos reíamos. Incluso hubo una viejita que en la calle nos quiso dar plata y le tuvimos que decir que no. (7:56)

Dentro de los planteamientos críticos del activismo de la discapacidad se demanda la necesidad de que los entornos se adapten a las características diversas de las personas o se generen equilibrios de ambas partes. Estos planteamientos, en muchos casos, son controvertidos, dependiendo si el cambio corporal es adquirido durante el transcurso de la vida o si son cuerpos diversos por una condición congénita. Estos últimos, refieren la necesidad de su reconocimiento como tal para participar desde sus diferencias sin ninguna necesidad de rehabilitación. Una activista ciega señala lo siguiente:

Lo que hay que hacer, creo yo, es tener un buen sistema de rehabilitación porque eso permite un puente súper importante en la inclusión. Si tú no estás rehabilitado no te puedes incluir, por más que la gente lo quiera. Si de un día para otro, yo pierdo el oído, pierdo la vista, me parto la columna, me cortan un pie, cómo voy a salir al otro día, a dármelas de incluida. No es así, hay que rehabilitarse primero, hay que tomar los 
mecanismos para vivir de una forma distinta, porque esto es así. (9:46)

Como adelantábamos, se puede apreciar una postura que representa a un grupo importante de activistas quienes exigen una cobertura universal de instancias de rehabilitación para alcanzar la meta de la "inclusión". Esta situación se plantea como una instancia ineludible para adquirir una participación social plena, a pesar de que finalmente, se reconoce que se deberá conformar una nueva vida.

En consecuencia, los devenires revisados que encarnan las personas que presentan diferencias corporales son parte de la medicalización de sus vidas cotidianas que "imponen una tecnología del manejo de sí y el manejo del cuerpo"(61) y que, por tanto, impacta en sus vidas íntimas y públicas. Desde ahí, los cuestionamientos de las y los activistas disidentes para interpelar el saber médico en todos sus procesos de autoritarismo con la dignidad de la vida que, como plantea Menéndez ${ }^{(24,25)}$, está rompiendo la histórica asimetría entre "profesionales" y "pacientes".

\section{CONCLUSIÓN}

Los itinerarios corporales de las y los activistas disidentes de la discapacidad que viven en Chile, nos permitieron analizar la situación de vulnerabilidad y vulneración corporal por la que transitan sus vidas en los dispositivos del modelo biomédico. En ese sentido, los itinerarios se deben reconocer como una posición ontológica de la diversidad. Esta cuestión, sin embargo, no es propia y únicamente de las personas etiquetadas como "discapacitadas", sino más bien, es una posición común de todas las personas, ya que somos temporalmente personas válidas y estamos continuamente expuestas a la fragilidad de la vulnerabilidad.

A pesar de ello, los dispositivos sanitarios tienden a fijar la vulnerabilidad como un tributo de determinados colectivos mediante la construcción del diagnóstico médico. Además, entendemos que esa vulnerabilidad se aprecia de manera diferenciada en función del género, en tanto el tratamiento y trato médico hacia las mujeres disidentes de la discapacidad se ve agudizado por habitar una condición genérica corpórea.

Asimismo, identificamos que la realidad del contexto chileno y su vínculo con las personas en situación de discapacidad se construye a través de lógicas precarizadas de un colectivo aún invisibilizado en su heterogeneidad de disputas y luchas. Esta situación, se refleja en la ausencia de políticas públicas con perspectiva de derechos humanos que reconozca a las personas disidentes de la discapacidad como agentes políticos de su condición y como codefinidores de dichas políticas, especialmente, en lo que se refiere a la identificación de sus necesidades, así como a las formas de atenderlas. A pesar de estas circunstancias y contextos, las y los activistas logran subvertir estas situaciones liberándose del disciplinamiento biopolítico de la sociedad neoliberal actual resistiendo a las vulneraciones del sistema.

\section{AGRADECIMIENTOS}

A la Comisión Nacional Científica y Tecnológica de Chile (CONICYT) por otorgar los fondos para emprender esta investigación, Folio No. 5489-2016 (2016-2019), y a las y los activistas que trabajan en Chile por hacer una sociedad mejor para todas y todos.

\section{REFERENCIAS BIBLIOGRÁFICAS}

1. Bauman Z. Vidas desperdiciadas: la modernidad y sus parias. Barcelona: Paidós; 2005.
2. Naciones Unidas. Convención Internacional de los Derechos de las Personas con Discapacidad [Internet]. Naciones Unidas; 2006 [citado 1 dic 2020]. Disponible en: https://tinyurl.com/49f6p5bn.

3. Alberich T. Movimientos sociales, responsabilidad corporativa e inclusión social en la globalización. Revista Internacional de Sociología. 2014;72(1):113-132. doi: 10.3989/ris.2013.03.04.

4. Oliver M. A new model of the social work role in relation to disability. En: Campling J, coord. A new perspective for social workers. London: Radar; 1981. p. 19-32. 
5. Rodríguez S, Ferreira M. Desde la dis-capacidad hacia la diversidad funcional un ejercicio de disnormalización. Revista Internacional de Sociología. 2010;68(2):289-309. doi:10.3989/ris.2008.05.22.

6. Pérez C. Una nueva antipsiquiatría: Crítica y conocimiento de las técnicas de control psiquiátrico. Santiago de Chile: Lom; 2012.

7. Le Breton D. Sociología del cuerpo. Madrid: Siruela; 2018.

8. Morris J. Encuentros con desconocidas: Feminismo y discapacidad. Madrid: Narcea; 1996.

9. Rucci AC. El surgimiento del Movimiento de Vida Independiente (MVI) en América Latina y su repercusión en la legislación de los países del Mercado Común del Sur (MERCOSUR). Integrar. 2015;(92):2-16.

10. Centro de Estudios Locos. Luchas anticuerdistas y movimiento Orgullo Loco en Chile [Internet]. Facebook. 2020 [citado 1 dic 2020]. Disponible en: https://tinyurl. com/2fejnetf.

11. Castillo Parada T. De la locura feminista al 'feminismo loco': Hacia una transformación de las políticas de género en la salud mental contemporánea. Investigaciones Feministas. 2019;10(2):399-316. doi: 10.5209/ infe.66502.

12. Esteban ML. Antropología del cuerpo: género, itinerarios corporales, identidad y cambio. Barcelona: Bellaterra; 2013

13. World Health Organization. The International Classification Functioning, Disability and Health. Geneva: WHO; 2001.

14. Palacios A. El modelo social de discapacidad: orígenes, caracterización y plasmación en la Convención Internacional sobre los Derechos de las Personas con Discapacidad. Madrid: Cinca; 2008.

15. Butler J. Cuerpos aliados y lucha política: hacia una teoría performativa de la asamblea. Madrid: Paidós; 2017.

16. Barton L. Discapacidad y sociedad. Madrid: Morata; 1998.

17. Barton L. Superar las barreras de la discapacidad. Madrid: Morata; 2008.

18. Ferreira M. Una aproximación sociológica a la discapacidad desde el modelo social: apuntes caracteriológicos. Reis. 2008;124:141-174.

19. Ferreira M. Discapacidad, globalidad y educación: ¿una nueva política del cuerpo? Revista Latinoamericana de Estudios sobre Cuerpos, Emociones y Sociedad. 2011;6(3):6-19.

20. Pié A, coord. Deconstruyendo la dependencia: propuesta para una vida independiente. Barcelona: UOC; 2012.
21. Pié A, coord. Por una corporeidad postmoderna: nuevos tránsitos sociales y educativos para la interdepencia. Barcelona: UOC; 2014

22. Butler J. Lenguaje, poder e identidad. Madrid: Síntesis; 2004.

23. Solé J, Pié A, coords. Políticas del sufrimiento y la vulnerabilidad. Barcelona: Icaria; 2018.

24. Menéndez EL. Modelo médico hegemónico: Reproducción técnica y cultural. Natura Medicatrix. 1998; 51:17-22

25. Menéndez EL. Modelo médico hegemónico: tendencias posibles y tendencias más o menos imaginarias. Salud Colectiva. 2020;16:e2615. doi: 10.18294/ sc. 2020.2615 .

26. Foucault M. El nacimiento de la clínica, una arqueología de la mirada médica. Buenos Aires: Siglo XXI Editores; 2008

27. Davis-Floyd R. Perspectivas antropológicas del parto y el nacimiento humano. Buenos Aires: Fundación Creavida; 2009

28. Agamben G. ¿Que es un dispositivo? Barcelona: Anagrama; 2015

29. Denzin N, Lincoln Y, coords. Manual de Metodología de investigación cualitativa, Vol. I: el campo de la investigación cualitativa. Barcelona: Gedisa; 2012.

30. Spinoza B. Ética demostrada según el orden geométrico. Madrid: Editora Nacional; 1980.

31. Vásquez ML, coord. Introducción a las técnicas cualitativas de investigación aplicadas en salud. Barcelona: Bellaterra; 2006

32. Tobosa-Martin M, Rogelo-Garcia J. Diseño para todos en la investigación social sobre personas con discapacidad. Reis. 2011;140:163-172. doi:10.5477/cis/ reis. 140.163

33. Clarke V, Braun V. Thematic Analysis. Journal of Positive Psychology. 2017;12(3):297-298. doi: 10.1080/ 17439760.2016.1262613.

34. Delgado J, Gutiérrez J. Métodos y técnicas cualitativas de investigación en ciencias sociales. Madrid: Síntesis; 1999.

35. Wittig M. El pensamiento heterosexual y otros ensayos. Madrid: Editorial Egales; 2006.

36. Butler J. Deshacer el género. Barcelona: Paidós; 2006.

37. Cabnal L. Recupero la alegría sin perder la indignación, como un acto emancipatorio y vital. Píkara [Internet]. 2019 [citado 1 dic 2020]. https://tinyurl.com/fvwwpvdj.

38. De Sousa-Santos B. Epistemologías del sur. Utopía y praxis Latinoamericana: Revista Internacional de Filosofía Iberoamericana y Teoría Social. 2011;16(54):17-39. 
39. Kielhofner G. Modelo de ocupación humana: Teoría y aplicación. Madrid: Médica Panamericana; 2011.

40. Castillo-Parada T. De la locura feminista al "feminismo loco": Hacia una transformación de las políticas de género en la salud mental contemporánea. Investigaciones Feministas. 2019;10(2):399-416. doi: 10.5209/ infe.66502.

41. Harvey D. Justicia, naturaleza y la geografía de la diferencia. Madrid: Traficantes de Sueños; 2018.

42. Maraña JJ, Lobato M. El movimiento de vida independiente en España. En: García-Alonso J. El movimiento de vida independiente. Experiencias Internacionales. Madrid: Fundación Luis Vives; 2003. p. 259-278.

43. Col.Lectiu Punt 6. Urbanismo feminista. Barcelona: Editorial Virus; 2019.

44. Camguilhem G. Lo normal y lo patológico. Madrid: Siglo XXI Editores; 2005.

45. Foucault M. Vigilar y castigar: Nacimiento de la prisión. Buenos Aires: Siglo XXI Editores; 2005.

46. Foucault M. El poder psiquiátrico. Buenos Aires: Fondo de Cultura Económica; 2007.

47. Basaglia F. ¿Que es la psiquiatría? Madrid: Guadarrama; 1977

48. Cooper D. ¿Quiénes son los disidentes? Valencia: Pre-Textos; 1978.

49. Delacampagne C. Antipsiquiatría. Barcelona: Mandrágora; 1978.

50. Laing R. La política de la experiencia. Barcelona: Crítica; 1967.

51. Szasz T. Ideología y enfermedad mental. Buenos Aires: Amorrortu; 1976
52. Antonucci G. El prejuicio psiquiátrico. Pamplona: Katakrak; 2018.

53. Sanmiquel L. Sujeción, des-sujeción y subjetivación del cuerpo discapacitado: entre el orgullo, la vergüenza y la superación (Tesis de pregrado). Barcelona: Universidad Autónoma de Barcelona; 2017.

54. Castillo-Parada T. Subjetividad y autonomía: significados y narrativas sobre la discontinuación de fármacos psiquiátricos. Salud Colectiva. 2018;14(3):513-529. doi: 10.18294/sc.2018.1861.

55. Falconí-Trávez D. Las entrañas del sujeto jurídico: Un diálogo entre la literatura y el derecho. Barcelona: Ediuoc; 2012.

56. Nussbaum M. Las fronteras de la justicia: consideraciones sobre la exclusión. Barcelona: Paidós; 2016.

57. Cea-Madrid J. Por el derecho a la locura: La reinvención de la salud mental en América Latina. Santiago de Chile: Proyección; 2018.

58. Arnau S. El modelo de asistencia sexual como derecho humano al auto-erotismo y el acceso al propio cuerpo: un nuevo desafío para la plena implementación de la filosofía de vida independiente. Intersticios: Revista Sociológica de Pensamiento Crítico. 2017;11(1):19-37.

59. Poblete S, Bozo N. Estudio exploratorio de violencia contra mujeres con discapacidad en tres pases de América Latina y el Caribe: Chile, Costa Rica y Uruguay. Santiago de Chile: Universidad Central; 2016.

60. Chile. Ley 20.422: Normas sobre igualdad de oportunidades e inclusión social de personas con discapacidad. Santiago de Chile: Ministerio de Planificación; 2010.

61. Braunstein N. Clasificar en psiquiatría. Ciudad de México: Siglo XXI Editores; 2013.

\section{FORMA DE CITAR}

Pino-Morán JA, Rodríguez-Garrido P, Zango-Martín I, Mora-Malo E. Subvertir la vulneración médica: itinerarios corporales disidentes de la discapacidad en Chile. Salud Colectiva. 2021;17:e3021. doi: 10.18294/sc.2021.3021.

Recibido: 23 jul 2020 | Versión final: 2 dic 2020 | Aprobado: 28 dic 2020 | Publicado en línea: 12 mar 2021

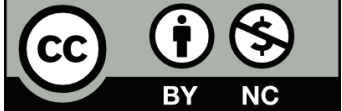

Esta obra está bajo una licencia de Creative Commons Reconocimiento-NoComercial 4.0 nternacional. Reconocimiento - Permite copiar, distribuir y comunicar públicamente la obra. A cambio, se debe reconocer y citar al autor original. No Comercial - Esta obra no puede ser utilizada con finalidades comerciales, a menos que se obtenga el permiso. 